\title{
Chronographic tethering: a technique for measuring prey survival time and testing predation pressure in aquatic habitats
}

\author{
Thomas J. Minello \\ National Marine Fisheries Service, Southeast Fisheries Center, Galveston Laboratory, 4700 Avenue U, Galveston, \\ Texas 77551, USA
}

\begin{abstract}
A chronographic system was developed to measure survival time of tethered prey and quantify predation pressure in aquatic habitats. The system incorporates a small digital clock with a pressure-sensitive triggering mechanism. Survival time is a continuous variable that can be analyzed with parametric statistical tests, and in comparison with presence/absence data normally obtained in tethering studies, this variable provides more information per tethered prey. The technique was tested using tethered brown shrimp Penaeus aztecus. The sensitivity of the triggering mechanism was set to ensure that shrimp escape behavior would not trigger the clock. In laboratory trials with pinfish Lagodon rhomboides as predators, triggering efficiency for predation events was measured at $65 \%$. A field experiment was also conducted in 3 estuarine habitats located in the Galveston Bay system of Texas, USA. On unstructured sand bottom the efficiency of the triggering mechanism was similar to that measured in the laboratory. Structure in seagrass and salt marsh habitats, however, appeared to affect triggering efficiency and reduced the number of usable observations in these habitats. Despite this complication, significant differences in survival time were detected. Predation pressure appeared to be lower in the seagrass and salt marsh habitats examined compared with nonvegetated sand bottom.
\end{abstract}

\section{INTRODUCTION}

Tethering techniques can be useful for examining the refuge value of habitats because mortality of tethered prey is due to both the effects of habitat structure on predation rates and to differences in predator populations. Predation pressure in different habitats has been measured using tethered crabs and gastropods (Heck \& Thoman 1981, Heck \& Wilson 1987, Wilson et al, 1987, 1990a, b), spiny lobsters (Herrnkind \& Butler 1986), and even small fishes (Shulman 1985, McIvor \& Odum 1988, Rozas \& Odum 1988, Rozas 1992). The procedure generally involves connecting the prey to a thin monofilament tether and staking the animal in various habitats. The observation made is whether the tethered animals have been eaten over some fixed time, and the percentage of animals eaten is often compared among habitats using chi-square or other tests of independence.
Comparisons among habitats using presence/absence data generally require the deployment of large numbers of tethered prey to obtain adequate statistical power. By converting the presence/absence observation to the continuous variable of survival time, the amount of information obtained per experimental animal can be increased. The use of survival time also reduces the dependence of tethering results on the experimental duration. If only the presence or absence of tethered animals is recorded, very short experiments can result in $0 \%$ predation in all habitats, and very long experiments can result in $100 \%$ predation in all habitats. Thus, selecting the appropriate experimental duration is critical in these studies. If survival time is measured, however, the experimental duration simply must be long enough to ensure that most prey are eaten; maximum survival time is dictated by the experimental duration.

Survival time for tethered prey is a continuousvariable observation that should reflect predation 
pressure. My objective was to develop a tethering system using inexpensive digital clocks to measure survival time. Similar systems have been developed to measure hook strike time in Pacific longline fisheries (Somerton et al. 1988, Boggs 1992). I tested my system in the laboratory and under field conditions with brown shrimp Penaeus aztecus as tethered prey. In the field, predation pressure was measured within 3 estuarine habitats: a Spartina alterniflora salt marsh, Halodule wrightii seagrass meadow, and on nonvegetated sand bottom.

\section{MATERIALS AND METHODS}

The timing devices were obtained from inexpensive (ca US $\$ 1$ per clock) digital clocks with adhesive backings; these clocks are commonly attached to walls and car interiors. Several types of clock mechanisms exist, and most could be adapted for tethering purposes; however, the type I used had some valuable characteristics. When the connection between the battery and the circuit board was broken and then restored, the clock displayed 12:00 h midnight. The clock would not begin to run, however, until the button that alternated the display of the date versus the time was pushed. Pushing this button completed an electrical connection between a spring-steel battery holder and the circuit board. Once the clock was started it would continue to run, and additional connections simply toggled the time versus the date on the digital display.

The triggering mechanism for the tethering system consisted of a simple switch. Bell wire was connected to the clock's circuit board and wrapped around a screw eye on a wooden mounting board (Fig. 1). The tether line was connected to the spring-steel battery holder of the clock. When the tether was pulled, as

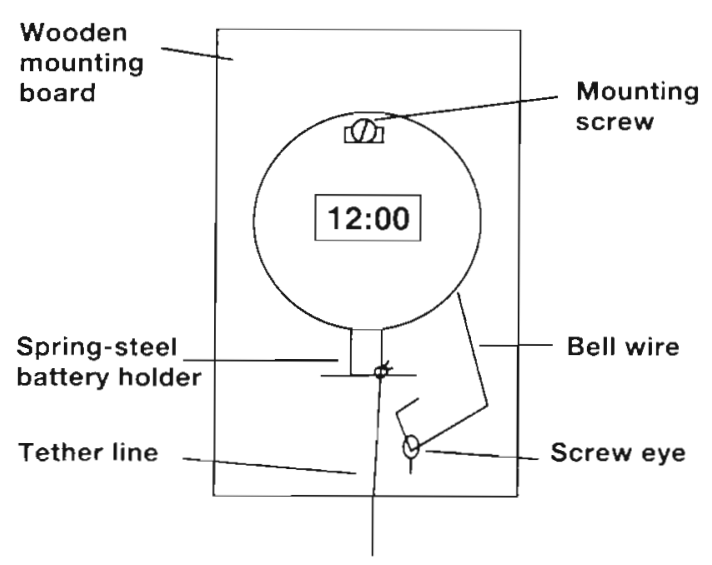

Fig. 1. Clock mechanism with simple switch for the chronographic tethering device would occur during a predation event, this battery holder contacted the bell wire, completed the electrical connection, and started the clock. The force required to trigger the mechanism was varied by adjusting the distance between the end of the bell wire and the spring steel. The timing mechanism and switch on the wooden mounting board were encased in a $15 \mathrm{~cm}$ long plastic pipe (38 mm i.d.) with 2 removable caps (Fig. 2). The tether line entered this canister through a hole in the lower cap and was connected to the switch.

Brown shrimp (35 to $50 \mathrm{~mm}$ total length, TL) were connected to the tether line using a noose in the monofilament thread. The noose was placed around the shrimp just behind the carapace and in front of the swimming legs and tightened with the knot positioned laterally. In the laboratory, this tethering did not increase shrimp mortality over 1 to $2 \mathrm{~d}$ periods and did not appear to affect burrowing behavior in a sand substratum. Tests were also conducted to determine the appropriate sensitivity for the switch mechanism. The force exerted by a $20 \mathrm{~g}$ weight $(0.196 \mathrm{~N})$ was chosen because brown shrimp of the above size could not trigger the mechanism at this setting, even when attempting to escape predators.

The efficiency of the triggering mechanism was tested in the laboratory using pinfish Lagodon rhomboides (163 to $186 \mathrm{~mm}$ TL) as predators. Efficiency of the technique was defined as the percentage of predation events that triggered the chronograph. A canister was suspended over a $1.8 \mathrm{~m}$ diameter fiberglass tank that contained seawater $(25 \mathrm{~cm}$ depth) and 6 pinfish. Individual tethered brown shrimp (total of 20 trials) were placed in the tank and observed visually as they were eaten. After each predation event the clock was checked to see if it had triggered at the appropriate time.

For deployment in the field, sections of plastic pipe were used to suspend the canister about $0.3 \mathrm{~m}$ above the water's surface. This supporting structure was arranged to keep the prey away from the pipe, both to prevent entanglement and to avoid increasing predation pressure by predators attracted to the structure of the pipe (Fig. 2). The length of the tether line was adjusted at each site to allow shrimp movement in a circular area on the bottom of approximately $1 \mathrm{~m}$ in diameter.

The field experiment was conducted on August 21 to 23, 1990 in Christmas Bay, Texas, USA, a part of the Galveston Bay system. The site is described in detail by Thomas et al. (1990). The Halodule wrightii seagrass bed in Christmas Bay extends approximately $300 \mathrm{~m}$ from the shoreline and is located between the shoreline marsh of Spartina alterniflora and the deeper nonvegetated sand bottom. Canisters with clocks were installed at 10 randomly selected locations along a 

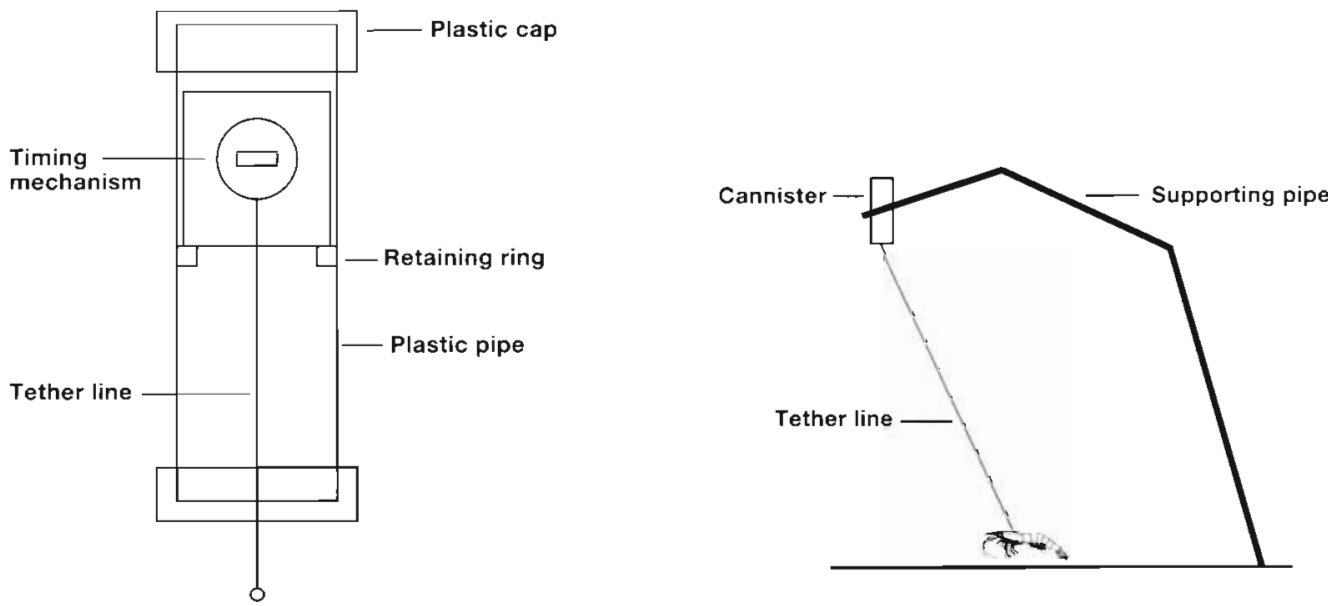

Fig. 2. Diagram of the plastic canister used to house the digital clock and the supporting structure used in field deployment

$1000 \mathrm{~m}$ transect in each habitat; transects were parallel to the shoreline. The nonvegetated transect was located 2 to $3 \mathrm{~m}$ away from the seagrass bed near the open bay, the seagrass transect ran through the center of the bed, and the marsh transect was located just inside the marsh/water interface. Marsh sites were modified by clipping the $S$. alterniflora stems to about $5 \mathrm{~cm}$ from the substrata in a circular area slightly larger than $1 \mathrm{~m}$ diameter; this modification was necessary to reduce tangling with the tether. The edge of this cleared area was located about $0.25 \mathrm{~m}$ from the marsh/water interface, and the canister was placed over the center of the area. Water depth at the time of tethering was at least $15 \mathrm{~cm}$ at the marsh sites, and the sites never completely drained during the experimental period. Seagrass and sand sites were not modified. Salinity during the study was $30 \mathrm{ppt}$, and the water temperature on August 22 between 14:00 and 15:00 h was $34^{\circ} \mathrm{C}$ in the seagrass and sand habitats and $37^{\circ} \mathrm{C}$ in the shallower marsh. Although water depth fluctuated with the tide, when the depth at the marsh sites was around $15 \mathrm{~cm}$, the water depth was around 60 and $85 \mathrm{~cm}$ at the seagrass and sand sites, respectively.

On August 21, 3 shrimp were tethered in each habitat between 16:00 and 17:30 h. On August 22, between $12: 30$ and $15: 30 \mathrm{~h}$, the tethers were checked, and 10 additional shrimp were tethered in each habitat. This second group of tethers was checked the following day. The time was recorded when each shrimp was tethered and when each tether was checked. When checking tethers, I also recorded the presence or absence of the shrimp and the status and time on the clock. From this information, the time that the clock was started (which I assumed was the time the shrimp was eaten) was calculated along with the number of minutes between deployment of the prey and the predation event (survival time). Differences among habitats in mean survival time were tested with analysis of variance (ANOVA) using SAS algorithms (PROC GLM).

\section{RESULTS}

In the laboratory, the survival time for tethered brown shrimp ranged from minutes to several hours. In the 20 trials, the tethering device was never triggered unless a shrimp was eaten. For 13 of the trials, the clock started within $71 \mathrm{~s}$ of the observed time of death (65\% efficiency). The pinfish ate the tethered shrimp in the remaining 7 trials without triggering the clock.

In the field experiment, clocks were checked approximately $1 \mathrm{~d}$ after deployment. Efficiency of the timing mechanism in recording the time of predation was estimated by comparing the number of clocks running after $1 \mathrm{~d}$ with the number of shrimp missing from tethers (Table 1). Twelve shrimp were missing from tethers in the salt marsh, but only 4 of the clocks had

Table 1. Tethering results for 3 habitats in Christmas Bay using brown shrimp Penaeus aztecus as prey

\begin{tabular}{lcccccc|}
\hline Habitat & No. of shrimp & $\begin{array}{c}\text { Clocks } \\
\text { running }\end{array}$ & $\begin{array}{c}\text { No. of } \\
\text { observ. }\end{array}$ & $\begin{array}{c}\text { Mean } \\
\text { survival } \\
\text { time (min) }\end{array}$ & $\begin{array}{c}\text { Standard } \\
\text { error }\end{array}$ \\
\hline Sand & 13 & 12 & 8 & 9 & 266.8 & 152.65 \\
Seagrass & 13 & 13 & 7 & 7 & 579.6 & 135.61 \\
Salt marsh & 13 & 12 & 4 & 5 & 711.6 & 218.30 \\
\hline
\end{tabular}


been started ( $33 \%$ efficiency). Of the 8 clocks that did not start in this habitat, 6 of the tether lines were tangled in the rigid vegetation stubble. In the seagrass bed, all 13 shrimp were missing from tethers while 7 clocks had started (54\% efficiency), and on sand bottom 12 shrimp were missing and 8 clocks had started $(67 \%)$.

For the calculation of mean survival time in the 3 habitats, instances where a tethered shrimp was missing but the clock was not running were considered as missing data and not included in the analysis. I considered it unlikely that clocks would have been started at a time other than when shrimp were eaten and assigned a survival time observation for each running clock. In the 2 instances where shrimp were still present when the tethers were checked, the clocks were not running. These shrimp were assigned a survival time of $1268 \mathrm{~min}$, the maximum time recorded in the study. Thus, survival times ranged from 0 to $1268 \mathrm{~min}$, and the maximum survival time was limited by the experimental duration. Mean survival time in the sand, seagrass, and salt marsh habitats was $266.8,579.6$, and $711.6 \mathrm{~min}$ respectively (Table 1 ). If the 2 observations assigned a value of $1268 \mathrm{~min}$ were omitted, these values were 141.6 (sand), 579.6 (seagrass) and $572.5 \mathrm{~min}$ (salt marsh).

An analysis of the residuals using the method of Shapiro \& Wilk (1965) indicated a significant departure from normality in the data ( $\mathrm{n}=21, \mathrm{p}=0.044)$. Both Bartlett's $(p=0.75)$ and Levene's ( $p=0.57)$ tests, however, indicated no significant departure from homogeneity for cell variances (Milliken \& Johnson 1984). A logarithmic transformation corrected the problem of normality $(p=0.75)$, but caused heterogeneity in the cell variances (Levene's test; $p<0.001$ ). Therefore, a square root transformation of the data was used in the ANOVA $_{;}$this transformation did not affect variance homogeneity (Levene's test; $p=0.21$ ) and normalized the data to the extent that there was no significant departure from normality at the $5 \%$ level $(p=0.067$ ).

Mean survival time was significantly different among the 3 habitats on the basis of an ANOVA on square-root transformed data $(F=3.9 ; \mathrm{df}=2,18 ; \mathrm{p}=$ 0.040 ). Mortality occurred significantly faster on the sand bottom than in the seagrass or salt marsh habitat (Least Significant Difference multiple range test, $\alpha=$ $0.05)$. There was no significant difference, however, in mean survival time between the 2 vegetated habitats. If I omitted the 2 observations that were assigned the maximum survival time of $1268 \mathrm{~min}$, the results were similar (ANOVA $;=6.8 ; \mathrm{df}=2,16 ; p=0.007$ ). For comparison with ANOVA, a Kruskal-Wallis nonparametric test for differences among the 3 habitats using the data in Table 1 was not significant at the $5 \%$ level (Chisquare $=5.3 ; \mathrm{df}=2 ; \mathrm{p}=0.07$ ).

\section{DISCUSSION}

Tethering experiments in estuarine habitats are valuable for measuring relative predation intensity (Heck \& Thoman 1981), but the available information is limited if only presence and absence data are recorded over a fixed time. The digital timing device described in this study is a simple and inexpensive method of measuring the continuous variable of survival time for tethered prey. Despite problems with efficiency of the triggering mechanism, survival time measured with this technique was useful in examining predation pressure within 3 estuarine habitats.

The efficiency of the triggering mechanism in recording the time of predation is related in part to the sensitivity of the switch mechanism. This sensitivity must be adjusted for different prey to prevent premature triggering of the clock by prey escape movements or other behaviors. I set the triggering force high enough in this study to ensure that brown shrimp would not prematurely trigger the clock. This sensitivity setting, however, also prevented some predation events from being recorded, and pinfish only triggered the clocks $65 \%$ of the time when eating tethered brown shrimp in the laboratory. A more careful analysis of the triggering sensitivity needed for a tethered prey probably could increase this triggering efficiency. The effort involved, however, might be more effectively spent by increasing the number of tethered prey used in a study. Unless triggering efficiency strongly interacts with predation pressure, a low triggering efficiency will simply reduce the amount of data obtained from a group of tethered prey.

In the field study, efficiency of the triggering mechanism in the unstructured sand habitat (67\%) was similar to the efficiency measured in the laboratory. In the relatively flexible structure of the seagrass bed, triggering efficiency was estimated at $54 \%$, but efficiency was reduced to $33 \%$ in the salt marsh habitat. Excessive tangling of tethers around rigid Spartina alterniflora stems appeared to have caused the additional failures of the mechanism in this habitat.

The utility of chronographic tethering in comparing predation pressure among habitats was apparent from the estimates of mean survival time obtained for tethered brown shrimp. Only about one-half of the shrimp tethered provided usable observations (21 out of 39). Despite this limited data set, however, an ANOVA indicated significant differences among the habitats in mean survival time for the shrimp. The results also emphasized the importance of experimental duration in tethering studies. My experimental duration of just under $1 \mathrm{~d}$ would have been too long to detect habitat differences if only the percentage of missing prey was recorded. All but 2 of the 39 tethered shrimp were 
missing at the end of the experiment; percentages of missing prey were $92 \%$ in sand and salt marsh habitats and $100 \%$ in the seagrass habitat.

Survival time for tethered brown shrimp was significantly longer in the seagrass bed and salt marsh than on nonvegetated sand bottom. These data agree with other tethering results that indicate predation intensity on crustaceans and mollusks is generally lower in submerged aquatic vegetation compared with nonvegetated bottom (Heck \& Thoman 1981, Herrnkind \& Butler 1986, Heck \& Wilson 1987, Wilson et al. 1987 , 1990a, b). My mensurative field experiment (sensu Hurlbert 1984), however, simply compared prey survival along transects in these habitats, and spatial variability within habitats could affect conclusions on overall habitat-related mortality. In addition, temporal variability, effects of prey size, and a variety of other factors could alter conclusions on relative prey survival in these habitats. The relative inefficiency of the triggering mechanism in structured habitats should not have affected the results unless low efficiency was related to high estimates of survival time in a habitat. My estimates of long survival times in vegetated habitats, however, are probably conservative (underestimating the actual values). If tangling of the tethers increased with the time shrimp spent in structured habitats, recording long survival times in these habitats would be unlikely. In addition, my removal of structure in the salt marsh to reduce tangling may have increased predation pressure on shrimp (Minello \& Zimmerman 1983, Minello et al. 1989) and reduced survival time for tethered prey in this habitat.

The use of tethering for the measurement of predation pressure may be most appropriate for prey without rapid escape requirements, such as crabs and gastropods (Heck \& Thoman 1981). Restrictions in preyescape response caused by the tether may affect the overall predation rates but should still allow habitat comparisons unless the effect of tethers varies among the habitats. Variable effects of tethers are most likely with highly motile prey that use different escape behaviors in different habitats. The effect of tethers on schooling fish, for example, may vary among habitats if schooling behavior is related to habitat structure. Tethering techniques may still be of value for these prey (McIvor \& Odum 1988, Rozas \& Odum 1988, Rozas 1992), but additional care must be taken in interpreting the results. Brown shrimp appear to be intermediate in their escape characteristics. Juveniles are often sedentary and burrow in the sediment to reduce predation (Minello et al. 1987) but also are dependent on rapid escape movements when attacked (Minello \& Zimmerman 1983). Barshaw \& Able (1990) found that tethered juvenile lobsters were unable to burrow in mud substrata, but I found no evidence for any similar effect of tethers on brown shrimp burrowing in the laboratory. In general, relationships between habitat characteristics and escape behaviors are not well known, and this would be a useful area for future research.

Acknowledgments. This research was supported by the Southeast Fisheries Science Center of the National Marine Fisheries Service and in particular by Edward Klima, former director of the Galveston Laboratory. I acknowledge the help of P. Sheridan in the development of the timing mechanism. T. Delaney, A. Goldberg, A. Innes, and R. Wooten conducted the laboratory tests and assisted in the field work. K. Heck, W. Richards, P. Sheridan, R. Zimmerman, and 3 anonymous reviewers provided valuable comments on earlier versions of the manuscript.

\section{LITERATURE CITED}

Barshaw, D. E., Able, K. W. (1990). Tethering as a technique for assessing predation rates in different habitats: an evaluation using juvenile lobsters Homarus americanus. Fish. Bull. U.S. 88: $415-417$

Boggs, C. H. (1992). Depth, capture time, and hooked longevity of longline-caught pelagic fish: timing bites of fish with chips. Fish. Bull. U.S. 90: 642-658

Heck, K. L., Thoman, T. A. (1981). Experiments on predatorprey interactions in vegetated aquatic habitats. J. exp. mar. Biol. Ecol. 53: 125-134

Heck, K. L., Wilson, K. A. (1987). Predation rates on decapod crustaceans in latitudinally separated seagrass communities: a study of spatial and temporal variation using tethering techniques. J. exp. mar. Biol. Ecol. 107: 87-100

Herrnkind, W. F., Butler, M. J. (1986). Factors regulating postlarval settlement and juvenile microhabitat use by spiny lobsters Panulirus argus. Mar. Ecol. Prog. Ser. 34: 23-30

Hurlbert, S. H. (1984). Pseudoreplication and the design of ecological field experiments. Ecol. Monogr. 54: 187-211

Mclvor, C. C., Odum, W. E. (1988). Food predation risk, and microhabitat selection in a marsh fish assemblage. Ecology 69: 1341-51

Milliken, G. A., Johnson, D. E. (1984). Analysis of messy data, Vol. 1. Designed experiments. Lifetime Learning Publ., Belmont, $\mathrm{CA}$

Minello, T J., Zimmerman, R. J. (1983). Fish predation on juvenile brown shrimp, Penaeus aztecus Ives: the effect of simulated Spartina structure on predation rates. J. exp. mar. Biol. Ecol. 72: 211-231

Minello, T. J., Zimmerman, R. J., Martinez, E. X. (1987). Fish predation on juvenile brown shrimp, Penaeus aztecus: effects of turbidity and substratum on predation rates. Fish. Bull. U.S. 85: 59-70

Minello, T. J., Zimmerman, R. J., Martinez, E. X. (1989). Mortality of young brown shrimp Penaeus aztecus in estuarine nurseries. Trans. Am. Fish. Soc. 118: 693-708

Rozas, L. P. (1992). Comparison of nekton habitats associated with pipeline canals and natural channels in Louisiana salt marshes. Wetlands 12: 136-146

Rozas, L. P., Odum, W E. (1988). Occupation of submerged aquatic vegetation by fishes: testing the roles of food and refuge. Oecologia 77: 101-106

Shapiro, S. S., Wilk, M. B. (1965). An analysis of variance test for normality (complete samples). Biometrika 52: 591-611 
Shulman, M. J. (1985). Recruitment of coral reef fishes: effects of distribution of predators and shelter. Ecology 66: $1056-1066$

Somerton, D., Kikkawa, B., Wilson, C. (1988). Hook timers to measure the capture time of individual fish. Mar. Fish. Rev. 50: $1-5$

Thomas, J. L., Zimmerman, R. J., Minello, T J. (1990). Abundance patterns of juvenile blue crabs (Callinectes sapidus) in nursery habitats of two Texas bays. Bull. mar. Sci. 46: $115-125$

This article was presented by K. L. Heck Jr, Dauphin Island, Alabama, USA
Wilson, K. A., Able, K. W., Heck, K. L. (1990a). Habitat use by juvenile blue crabs: a comparison among habitats in southern New Jersey. Buil. mar. Sci. 46: 105-114

Wilson, K. A., Able, K. W., Heck, K. L. (1990b). Predation rates on juvenile blue crabs in estuarine nursery habitats: evidence for the importance of macroalgae (Ulva lactuca). Mar. Ecol. Prog. Ser. 58: 243-251

Wilson, K. A., Heck, K. L., Able, K. W. (1987). Juvenile blue crab, Callinectes sapidus, survival: an evaluation of eelgrass, Zostera marina, as refuge. Fish. Bull. U.S. 85: 53-58

Manuscript first received: December 12, 1992 Revised version accepted: June 29, 1993 